UNIVERSITAS AHMAD DAHLAN GENRE

http://journal2.uad.ac.id/index.php/genre/index

\title{
FRASA ADJEKTIVAL DALAM RUBRIK OPINI SURAT KABAR HARIAN DAN KEDAULATAN RAKYAT EDISI OKTOBER 2017 DAN KAITANNYA DENGAN PEMBELAJARAN TEKS DESKRIPSI KELAS VII
}

\author{
Iswatmia1, Sudarminib1 \\ ${ }^{2}$ Program Studi Pendidikan Bahasa dan Sastra Indonesia FKIP, UAD \\ b Program Studi Pendidikan Bahasa dan Sastra Indonesia FKIP, UAD \\ Iiswatmii@gmail.com_; sudarmini@pbsi.uad.ac.id
}

\begin{tabular}{l}
\hline${ }^{a}$ Program Studi Pendidikan Bahasa dan \\
Sastra Indonesia FKIP, UAD \\
\hline Sejarah artikel: \\
Diterima \\
Revisi \\
Dipublikasikan
\end{tabular}

\section{Kata kunci:}

frasa adjektival,

teks deskripsi,

opini

\section{ABSTRAK}

Penggunaan frasa adjektival sebagai salah satu unsur pembentuk kalimat yang terdapat dalam susunan tata bahasa sebagai salah satu komponen penting yang memengaruhi pemahaman maksud dalam komunikasi tulis. Penelitian ini bertujuan mendeskripsikan fungsi klausa yang diduduki frasa adjektival, pola frasa adjektival, hubungan makna antarunsur frasa adjektival, dan kaitan frasa adjektival dengan pembelajaran teks deskripsi kelas VII. Penelitian ini ialah penelitian deskriptif kualitatif. Pengumpulan data dilakukan dengan metode simak dilanjutkan dengan teknik dasar sadap dan teknik lanjutan catat. Data dianalisis dengan metode agih, teknik dasar Bagi Unsur Langsung (BUL), dan teknik lanjutan lesap, ganti, dan sisip. Hasilnya, I) Fungsi subjek sebanyak 7, fungsi predikat sebanyak 73 , fungsi objek sebanyak 22 , dan fungsi keterangan sebanyak $76 ; 2)$ Terdapat 24 pola frasa adjektival yang ditemukan, 9 pola lama dan I4 pola frasa adjektival baru; 3) Terdapat 7 hubungan makna antarunsur frasa adjektival dengan rincian, penjumlahan sebanyak 24, pemilihan sebanyak 4, ragam sebanyak 28 , negatif sebanyak 35 , aspek sebanyak 17 , tingkat sebanyak 56, sedangkan sebanyak I4 merupakan hubungan makna temuan baru yaitu campuran; dan 4) Penelitian ini dikaitkan dengan pembelajaran teks deskripsi kelas VII pada KD 3.2 dan KD 4.2 yang dituangkan dalam Rencana Pelaksanaan Pembelajara (RPP) dan modul yang berjudul Memahami Frasa Adjektival melalui Teks Deskripsi.

Keywords:

adjektival phrase,

description text,

opinion

\begin{abstract}
This study aims to describe the function of clauses occupied by adjunctival phrases, adjunctival phrase patterns, meaning relations between adjunctival phrase elements, and relation of adjunctival phrases with class VII text description learning. This research is a qualitative descriptive study. Data collection was carried out using the listening method followed by the basic tapping technique and the advanced note-taking technique. Data were analyzed by the method of distribution, the basic technique for direct elements (BUL), and advanced techniques for fading, dressing and inserting. As a result, I) 7 subject functions, 73 predicate functions, 22 object functions, and 76 information functions; 2) There are 24 adjunctival phrase patterns found, 9 old patterns and 14 new adjunctival phrase patterns; 3) There are 7 meaningful relationships between adjective phrase elements with details, 24 totaling, selection 4, 28 variations, 35 negative, I7 aspects, 56 levels, while I4 represent relationships of new findings meaning that is mixed; and 4) This research is related to the learning of text description class VII in KD 3.2 and KD 4.2 as outlined in the Learning Implementation Plan (RPP) and a module entitled Understanding Adjective Phrases through Text Description.
\end{abstract}

\section{Pendahuluan}

Menurut Alwi (2010: 35-56) Bahasa Indonesia memiliki empat kategori sintaksis utama: (I) verba, (2) nomina, (3) adjektiva, (4) dan adverbia. Pada tataran sintaksis, adjektiva dan perkembangannya disebut frasa adjektival, begitu juga kategori lainnya.

Penggunaan frasa adjektival sebagai salah satu unsur pembentuk kalimat yang terdapat dalam susunan tata bahasa sebagai salah 
komponen penting yang memengaruhi pemahaman maksud dalam komunikasi tulis.

Menurut Chaer (2015: 48) membagi kelas kata menjadi dua macam, yaitu kata- kata dari kelas terbuka dan kata-kata dari kelas tertutup. Disebut kelas terbuka karena anggota kelas ini dapat bertambah atau berkurang sewaktu-waktu sesuai dengan perkembangan budaya dan kemasyarakatan. Kedudukan dan fungsi dari kelas kata terbuka yakni sebagai pengisi fungsifungsi sintaksis. Sementara itu, dari anggota kelas tertutup kecil kemungkinannya untuk bertambah.

Kata berkategori adjektifa merupakan kelas kata terbuka, artinya anggota kelas kata adjektifa dapat bertambah atau berkurang sewaktu-waktu sesuai dengan perkembangan budaya dan kemasyarakatan. Kedudukan adjektifa dalam fungsi sintaksis adalah sebagai pengisi fungsi predikat, di samping sebagai "pengiring" kategori nomina.

Salah satu jenis frase yang masih sering dibicarakan sampai saat ini yaitu frase adjektival, karena beberapa pendapat para ahli mengemukakan pengertian yang tidak selaras. Kridalaksana (2007: 46) menyatakan bahwa adjektiva berperilaku mirip dengan verba, yakni sama-sama bisa didampingi tidak dalam konstruksi, tetapi berlain daripada verba, juga dapat didampingi agak dalam konstruksi. Sementara itu, Ramlan (I985: 50) berpendapat bahwa adjektiva merupakan bawahan dari verbal.

Tujuan penelitian ini adalah (I) mendeskripsikan fungsi klausa yang diduduki frasa adjektival dalam rubrik opini pada surat kabar harian Kedaulatan Rakyat edisi Oktober 2017, (2) mendeskripsikan pola frasa adjektival, (3) mendeskripsikan hubungan makna antarunsur frasa adjektival, dan (4) mendeskripsikan kaitan frasa adjektival dengan pembelajaran teks deskripsi kelas VII.

\section{Metode}

Jenis penelitian ini ialah penelitian deskriptif kualitatif. Subjek penelitian ini adalah rubrik Opini surat kabar harian Kedaulatan Rakyat edisi Oktober 2017, sedangkan objek penelitian ini adalah frasa adjektival.
Metode pengumpulan data yaitu metode simak dengan teknik dasar sadap dan teknik lanjutan catat. Teknik analisis data yaitu metode agih dengan menggunakan teknik dasar Bagi Unsur Langsung (BUL) dan teknik lanjutan lesap, ganti, dan sisip.

\section{Hasil dan pembahasan}

Berdasarkan analisis dari data yang telah dikumpulkan, diperoleh empat bahasan rumusan masalah. Empat bahasan tersebut sebagai berikut.

\section{Fungsi Klausa yang Diduduk Frasa Adjektival}

Fungsi merupakan suatu tempat kosong yang diisi oleh bentuk tertentu yang disebut kategori dan diisi oleh makna tertentu yang disebut peran. Dalam penelitian ini terdapat empat fungsi sebagai berikut.

a. Subjek

Frekuensi fungsi subjek dalam penelitian ini sebanyak 7 data.

(I) berperilaku tidak jujur ini

S

merupakan salah satu dampak

$\mathrm{P}$

dari perkembangan perangkat

$\underline{\text { teknologi informasi dan komunikasi }}$ (KR/I6 Okt 2017)

Frasa adjektival tidak jujur adalah frasa yang menduduki fungsi subjek, dapat dibuktikan dengan kata tanya apa yang jawabanya merupakan berperilaku tidak jujur.

Frasa tidak jujur berperan sebagai atributif dari frasa verbal berperilaku tidak jujur. Jadi frasa ini adalah frasa adjektival atributif yang menduduki frasa lain.

b. Predikat

Frekuensi fungsi predikat dalam penelitian ini sebanyak 73 data.

(2) $\frac{\text { rakyat }}{\text { sudah cukup lelah }}$

( KR/06 Okt 2017) 
Frasa sudah cukup lelah merupakan frasa adjektival yang menduduki inti dari fungsi predikat, artinya frasa tersebut dapat mengisi fungsi predikat secara utuh.

c. Objek

Frekuensi fungsi objek dalam penelitian ini sebanyak 22 data.

(3) setiap penyaji hanya diberi alokasi

waktu yang sangat singkat

$\mathrm{O}$

(KR/I6 Okt 2I07)

Frase adjectival sangat singkat menduduki sebagai atributif dalam fungsi objek. Frasa sangat singkat sebagai atributif dari frasa alokasi waktu yang sangat singkat.

\section{d. Keterangan}

Frekuensi fungsi keterangan dalam penelitian ini sebanyak 73 data.

(4) publik akan dengan mudah

S $\quad \mathrm{K}$

mengakses data pengurus partai

$\mathrm{P}$

(KR/I8 Okt 2017)

Frasa adjektival tersebut menduduki fungsi keterangan. Frasa akan dengan mudah merupakan frasa inti yang mengisi fungsi keterangan aspek.

Berdasarkan data penelitian yang ditemukan, frasa adjektival dapat mengisi fungsi selain fungsi predikat. Namun, juga dapat mengisi fungsi subejk, objek, dan keterangan.

\section{Pola Frasa Adjektival}

Berdasarkan penelitian yang dilakukan pola frase adjektival yang ditemukan adalah 9 jenis pola yang sama dengan pendapat Kridalaksana dan $\mathrm{I} 4$ jenis pola baru.

a. Pola FA: $A+V$

(5) cukup berkualitas (KR/4/Okt/I7).

Mempunyai frekuansi sebanyak 4 data. Kata cukup sebagai kategoriAdjektival dan kata berkualitas merupakan kategori verbal.

b. Pola FA: $\mathrm{AI}+\mathrm{A} 2+\mathrm{A} 3$
(6) kuat, licin, dan sistematis (KR/9/Okt/I7).

Mempunyai frekuensi 6 data. ketiga unsur kata tersebut merupakan kategori adjektival.

c. Pola FA: Pron+A

(7) begitu pelit (KR/5/Okt/I7).

Mempunyai frekuensi data sebanyak 3 data. kata brgitu merupakan kategori pronomina atau kata ganti, sedangkan kata pelit merupakan kategori adjektival.

d. Pola FA: $A d v+N+A$

(8) tanpa persenjataan lengkap

(KR/6/Okt/I7).

Mempunyai frekuensi sebanyak 3 data. kata tampa merupakan kategori adverbia, persenjataan merupakan kategori nomina, dan kata lengkap merupakan kategori adjekival.

e. Pola FA: Partikel+A

(9) sejak lama (KR/9/Okt/I7).

Mempunyai frekunsi data sebanyak 4 data. kata sejak merupakan kategori partikel dan kata lama merupakan adjektivs.

f. Pola FA: $\mathrm{Adv}+\mathrm{V}+\mathrm{A}$

(I0) tidak sampai tuntas (KR/I0/Okt/I7).

Mempunyai frekuensi sebanyak 6 data. Kata tidak merupakan kategori adverbia, sampai merupakan kategori verba, dan kata tuntas merupakan kategori adjektiva.

g. Pola FA: $\mathrm{AI}+\mathrm{A} 2+\mathrm{A} 3+\mathrm{A} 4$

(II) promotif, preventif, kuratif, dan rehabilitatif(KR/I0/Okt/I7)

Mempunyai frekuensi sebanyak I data. keempat unsur frasa tersebut merupakna kategori kata adjektiva.

h. Pola FA: Adv+Pron+A

(I2) tidak begitu jauh (KR/I6/Okt/I7).

Mempunyai frekuensi I data. Kata tidak merupakan kategori kata adverbia, dengan merupakan kategori kata pronomina, dan kata jauh merupakan kategori adjektiva.

i. Pola FA: $\mathrm{Adv}+$ Prep $+\mathrm{A}$ 
(I3) akan dengan jelas (KR/I8/Okt/I7).

Mempunyai frekuensi 2 data. Kata akan merupakan kategori kata adverbia, dengan merupakan kategori kata preposisi, dan kata jelas merupakan kategori kata adjektiva.

j. Pola FA: Adv+Prep+A+A

(14) akan dengan cepat dan mudah

(KR/I8/Okt/I7).

Mempunyai frekuensi 2 data. Kata akan merupakan kategori kata adverbia, dengan merupakan kategori kata preposisi, san kata cepat dan mudah merupakan kategori kata adjektival.

k. Pola FA: $\mathrm{Adv}+\mathrm{Adv}+\mathrm{A}+\mathrm{A}+\mathrm{A}$

(I5) akan lebih kreatif, inovatif dan mandiri (KR/I8/Okt/I7).

Mempunyai frekuensi I data. Kata akan dan lebih merupakan kategori kata adverbia, inovatif dan mandiri merupakan kategori kata adjektiva.

1. Pola FA: $A d v+V+N+A$

(I6) tidak ada rasa takut

(KR/27/Okt/I7).

Mempunyai frekuensi I data. Kata tidak merupakan kategori kata adverbia, ada merupakan kategori verba, rasa merupakan kategori kata nomina, dan kata takut merupakan kategori adjektiva.

m. Pola FA: Adv+A red.

(I7) secara besar-besaran

$(\mathrm{KR} / 3 / \mathrm{Okt} / \mathrm{I} 7)$.

Mempunyai frekuensi I data. Kata secara merupakan kategori kata adverbia, dan kata besar-besaran merupakan kategori adjektival reduplikasi.

n. Pola FA: N+A

(18) luar biasa
(KR/20/Okt/I7).

Mempunyai frekuensi I data, kata luat merupakan kategori kata nomina dan kata biasa merupakan kategori adjektival. Frasa ini merupakan kata turunan yang membentuk adjektiva.

Berdasarkan hasil temuan mengenai pola frasa adjektival dapat disimpukan bahwa kategori kata yang paling sering bersanding dengan kategori adjektival adalah kategori adverbial atau kata keterangan, baik hanya engan kategori adverbial saja atau dengan beberapa kategori lainnya.

\section{Hubungan Makna Antarunsur Frasa Adjektival}

Ramlan (2005: I3I) menggolongkan kata sifat atau adjektiva termasuk ke dalam golongan verba. Maka dari itu diperoleh hubungan antarunsur frasa adjektival sebagai berikut (Ramlan, 2005: I56-I6I).

a. Hubungan Makna Penjumlahan

Hubungan makna penjumlahan memiliki frekuensi kemunculan sebanyak 24 data.

(I9) Kurikulum terlalu rigid dan kaku (KR/I I/Okt/I7)

Frase adjektival yang mempunyai hubungan makna penjumlahan ini dapat dilihat dari unsur pembangunnya yang sama-sama menduduki unsur pusat serta terdapat pengunaan konjungsi 'dan'.

b. Hubungan Makna Pemilihan

Hubungan makna pemilihan mempunyai frekuensi sebanyak 4 data.

(20) kalau anaknya terlihat nakal, sadar atau tunduk, pihak sekolah yang disalahkan (KR/I I/Okt/I7)

Unsur pembangunnya sam-sama menduduki unsur pusat dan terdapat penggunaan konjungsi 'atau' yang menyatakan pemilihan.

c. Hubungan Makna Ragam 
Hubungan makna ragam mempunyai frekunsi sebanyak 28 data.

(2I) Sekolah juga harus gencar menanamkan pemahaman kepada anak didik (KR/II/Okt/I7)

Salah satu ciri dari makna keharusan adalah penggunaan kata 'harus', seperti pada frasa di atas yang berarti mmiliki hubungan keharusan.

d. Hubungan Makna Negatif

Hubungan makna negatif mempunyai frekuensi 35 data.

(22) ekonomi tidak terlalu kuat

(KR/3/Okt/I7)

Klausa di atas terdapat kata 'tidak' yang menyatakan pengingkaran, penolakan, atau penyangkalan, maka dari itu kalusa tersebut memiliki hubungan makna negatif.

e. Hubungan Makna Aspek

Hubungan makna aspek mempunyai frekuensi 17 data.

(23) 'terapi' krisis kebangsaan sedang akut

(KR/23/Okt/17)

Hubungan makna aspek pada frasa adjektival dapat dilihat adanya penanda kata pada unsurnya, seperti pada frasa di atas yang terdapat kata 'sedang' yang menyatakan keadaan adjektiva.

f. Hubungan Makna Tingkat

Hubungan makna tingkat mempunyai frekuensi 56 data.

(24) tidak jarang pembawa acara topik kuliner di televisi hanya menggelontorkan frase 'enak sekali' dan 'luar biasa' (KR/20/Okt/I7)

Kata sekali merupakan kata yang menyatakan hubungan makna tingkat.

g. Hubungan Makna Campuran

Hubungan makna campuran mempunyai frekuansi I4 data. Dapat dikatakan sebagai hubungan makna campuran apabila frasa adjektival tersebut memiliki dua atau lebih dari keenam hubungan makna yang telah ada.

(25) bisnis ini tidak akan lancar (KR/II/Okt/I7)

Hubungan makna campuran frasa adjektival di atas adalah makna negatif dan makna aspek. Kata 'tidak' menyatakan sangkalan terhadap suatu keadaan yang memiliki makna negatif. Sementara itu, kata 'akan' menyatakan bahwa suatu keadaan akan berlangsung.

Hubungan makna yang ditemukan dalam penelitian ini terdapat tujuh hubungan makna. Enam diantarannya merupakan hubungan makna berdasarkan teori Ramlan, sedangkan satu hubungan makna terakhri yaitu hubungan makan campuran adalah temuan baru dalam penelitian ini.

\section{Kaitan Frasa Adjektival dengan Pembelajaran Teks Deskripsi Kelas VII}

Penelitian ini dapat dikaitakan dengan pembelajaran teks deskripsi kelas VII. Hal ini dapat dilihat dari kurikulum 2013 revisi 2017 pada KD 3.2 tentang struktur dan kaidah kebahasaan teks deskripsi dan KD 4.2 tentang menyajikan teks deskripsi secara lisan maupun tulis. Hasil peneilitian dituangkan dalam Rencana Pelaksanaan Pembelajaran(RPP) dan luaran berupa modul yang berjudul Memahami Frasa Adjektival melalui Teks Deskripsi.

\section{Simpulan}

Fungsi klausa yang diduduki frasa adjektival ditemukan sebanyak empat fungsi, yaitu fungsi subjek, fungsi predikat, fungsi objek, dan fungsi keterangan. Pola frasa adjektival yang ditemukan sebanyak 23 jenis pola, 9 pola merupakan pola lama dan I4 pola merupakan pola baru. Pola baru tersebut meliputi FA: A+V, FA: AI+A2+A3, FA: Pron+A, FA: $\mathrm{Adv}+\mathrm{N}+\mathrm{A}, \mathrm{FA}$ : Partikel+A, FA: $\mathrm{Adv}+\mathrm{V}+\mathrm{A}$, FA: $\mathrm{AI}+\mathrm{A} 2+\mathrm{A} 3+\mathrm{A} 4, \quad \mathrm{FA}: \mathrm{Adv}+\operatorname{Pron}+\mathrm{A}, \quad \mathrm{FA}:$ Adv + Prep $+A, \quad$ FA: $\quad A d v+$ Prep $+A+A, \quad F A$ : $\mathrm{Adv}+\mathrm{Adv}+\mathrm{A}+\mathrm{A}+\mathrm{A}, \quad \mathrm{FA}: \quad \mathrm{Ad} v+\mathrm{V}+\mathrm{N}+\mathrm{A}, \quad \mathrm{FA}:$ $A d v+A$ red, dan FA: $N+A$. Hubungan makna antarunsur frasa adjektival meliputi hubungan makna penjumlahan, hubungan makna pemilihan, hubungan makna ragam, hubungan makna negatif, hubungan makna aspek, hubungan makna tingkat, dan hubungan makna campuran. Kaitan frasa adjektival dengan teks deskripsi kelas VII dituangkan dalam 
RPP dan modul yang berjudul Memahami Frasa Adjektial melalui Teks Deskripsi

\section{Persantunan}

Rasa syukur selalu saya panjatkan kepada Allah Swt., yang memberikan kesehatan, kelancaran berpikir, serta rezeki yang selalu tercukupi untuk menyelesaikan artikel ini. Terima kasih saya ucapkan kepada kedua orangtua saya yang telah memberikan semangat dukungan secara moral maupun materil untuk keberhasilan putrinya.

Terima kasih kepada seluruh dosen Program Studi Pendidikan Bahasa dan Sastra Indonesia yang telah memberikan ilmu dan terima kasih kepada Universitas Ahmad Dahlan yang telah menjadi tepat ternyaman utuk menimba ilmu.

\section{DaftarPustaka}

Alwi, Hasan dkk. 20I0. Tata Bahasa Baku Bahasa Indonesia. Jakarta: Balai Pustaka.

Chaer, Abdul. 2015. Sintaksis Bahasa Indonesia. Jakarta: Rineka Cipta.

Kridalaksana, Harimurti. 2007. Kelas Kata Dalam Bahasa Indonesia. Jakarta: Gramedia Pustaka Utama.

Ramlan, M. 2005. Sintaksis. Yogyakarta: CV. Karyono. 